\title{
Performance of residential air-conditioning systems with flow maldistribution in fin- and-tube evaporators
}

Kærn, Martin Ryhl; Brix, Wiebke; Elmegaard, Brian; Larsen, Lars Finn Sloth

Published in:

International Journal of Refrigeration

Link to article, DOI:

10.1016/j.jirefrig.2010.12.010

Publication date:

2011

Document Version

Early version, also known as pre-print

Link back to DTU Orbit

Citation (APA):

Kærn, M. R., Brix, W., Elmegaard, B., \& Larsen, L. F. S. (2011). Performance of residential air-conditioning systems with flow maldistribution in fin-and-tube evaporators. International Journal of Refrigeration, 34(3), 696706. https://doi.org/10.1016/j.ijrefrig.2010.12.010

\section{General rights}

Copyright and moral rights for the publications made accessible in the public portal are retained by the authors and/or other copyright owners and it is a condition of accessing publications that users recognise and abide by the legal requirements associated with these rights.

- Users may download and print one copy of any publication from the public portal for the purpose of private study or research.

- You may not further distribute the material or use it for any profit-making activity or commercial gain

- You may freely distribute the URL identifying the publication in the public portal 


\title{
Performance of residential air-conditioning systems with flow maldistribution in fin-and-tube evaporators
}

\author{
Martin Ryhl Kærn, ${ }^{\mathrm{a}, \mathrm{b}, *}$, Wiebke Brix ${ }^{\mathrm{b}}$, Brian Elmegaard ${ }^{\mathrm{b}}$, Lars Finn Sloth Larsen ${ }^{\mathrm{a}}$ \\ ${ }^{a}$ Danfoss A/S, Refrigeration and Air-Conditioning, Nordborgvej 81, DK-6430 Nordborg, Denmark \\ ${ }^{b}$ Department of Mechanical Engineering, Technical University of Denmark, Nils Koppels Allé Bygn. 403, DK-2800 Lyngby, Denmark
}

\begin{abstract}
Refrigerant and airflow maldistribution in fin-and-tube evaporators for residential air-conditioning was investigated with numerical modeling. Fin-and-tube heat exchangers usually have a pre-defined circuitry. However, the objective in this study was to perform a generic investigation of each individual maldistribution source in an independent manner. Therefore, the evaporator and the condenser were simplified to be straight tubes for the purposes of this study. The numerical model of the R410A system, its verification and an investigation of individual maldistribution sources are presented in this paper. The maldistribution sources of interest were: inlet liquid/vapor phase distribution, feeder tube bending and airflow distribution. The results show that maldistribution reduced the cooling capacity and the coefficient of performance of the system. In particular, different phase distribution and non-uniform airflow distribution reduced the performance significantly. Different feeder tube bendings only caused a minor decrease in performance.
\end{abstract}

Keywords: Distribution, Air conditioning, Finned tube, Modelling, Simulation

\section{Nomenclature}

\section{Roman}

$A$ Cross-sectional area $\left(\mathrm{m}^{2}\right)$

$C$ Capacitance flow $\left(\mathrm{W} \mathrm{K}^{-1}\right)$

$c_{p}$ Specific heat capacity $\left(\mathrm{J} \mathrm{kg}^{-1} \mathrm{~K}^{-1}\right)$

$F_{w}$ Wall friction force $\left(\mathrm{N} \mathrm{m}^{-3}\right)$

$F_{x}$ Phase distribution parameter (-)

$F_{\text {air }}$ Airflow distribution parameter (-)

$F_{\mathrm{ft}}$ Feeder tube bending parameter (-)

$g$ Gravitational acceleration $\left(\mathrm{m} \mathrm{s}^{-2}\right)$

$\bar{h}$ Specific in-situ mixture enthalpy $\left(\mathrm{J} \mathrm{kg}^{-1}\right)$

$h$ Specific enthalpy, mixed-cup enthalpy $\left(\mathrm{J} \mathrm{kg}^{-1}\right)$

$M$ Mass (kg)

$\dot{m}$ Mass flow rate $\left(\mathrm{kg} \mathrm{s}^{-1}\right)$

NTU Number of transfer units (-)

$P$ Channel perimeter $(\mathrm{m})$

$p$ Pressure $(\mathrm{Pa})$

$\dot{Q}$ Heat flow rate $(\mathrm{W})$

$q_{w}^{\prime \prime}$ Wall heat flux $\left(\mathrm{W} \mathrm{m}^{-2}\right)$

$T$ Temperature (K)

$t$ Time (s)

\footnotetext{
5215.

*Corresponding author. Tel: +45 4525 4121; Fax: +45 4593

Email address: pmak@mek.dtu.dk (Martin Ryhl Kærn)
}

$V$ Velocity $\left(\mathrm{m} \mathrm{s}^{-1}\right)$

$x$ Vapor quality (-)

$z$ Axial channel length (m)

Greek

$\alpha$ Void fraction (-)

$\epsilon$ Effectiveness (-)

$\rho$ Density $\left(\mathrm{kg} \mathrm{m}^{-3}\right)$

$\bar{\rho}$ Mixture density $\left(\mathrm{kg} \mathrm{m}^{-3}\right)$

$\rho^{\prime}$ Momentum density $\left(\mathrm{kg} \mathrm{m}^{-3}\right)$

$\theta$ Angle to horizontal plane (deg.)

Subscripts

$a$ Air

acc Accelerational

fr Frontal

fric Friction

$\mathrm{ft}$ Feeder tube

$f$ Saturated liquid

$g$ Saturated gas

$H$ Homogeneous

$m$ Mean

$r$ Refrigerant

$s h$ Superheat

$w$ Wall

Preprint submitted to International Journal of Refrigeration 


\section{Introduction}

Reduction of energy consumption and refrigerant charge in refrigeration systems is becoming increasingly important for environmental, legislative and economical reasons. Therefore, compact dry-expansion multi-channel heat exchangers are of interest for future refrigeration technology.

The use of multi-channels in evaporators gives rise to refrigerant maldistribution, which has been shown to reduce the cooling capacity and coefficient of performance (COP) of cooling systems. Payne and Domanski (2003) showed that the capacity dropped as much as $41 \%$ and $32 \%$ for two different fin-and-tube evaporators due to variable superheat values between the circuits when circuit pressure drops were induced and the overall superheat was fixed at $5.6^{\circ} \mathrm{C}$.

Typically, fin-and-tube A-coils are employed in residential air conditioning (RAC) systems as the indoor coil, which is the evaporator. Two coils form an Ashape, as the name indicates, in order to increase the frontal area of the evaporator. A drawback is that the airflow becomes non-uniform to the coil, resulting in airflow maldistribution. In a numerical study by Lee et al. (2003), non-uniform airflow profiles reduced the capacity of the evaporator up to $6 \%$. The airflow might also create a recirculation zone in the lower part of the coil as pointed out by AbdelAziz et al. (2008), who carried out simulations of the airflow through an A-coil using computational fluid dynamics. These recirculation zones in the coil led to a reduction in the cooling capacity since the recirculated airflow were not exchanged.

Mixing of the refrigerant phases and orientation of the refrigerant distributor is also important in order to distribute the refrigerant phases equally. The density differences among the liquid and vapor phases indicate that the best flow orientation is vertical. However, this orientation does not always ensure optimal refrigerant distribution. Nakayama et al. (2000) studied a new type of distributor that had a capillary mixing space instead of the orifice of a conventional distributor. They showed that a vertical inclination angle of 15 degrees reduced the capacity of the evaporator by $1.5 \%$ when they used the conventional distributor. However, the new type of distributor only had a reduction of $0.4 \%$. The better mixing in the new type of distributor resulted in a capacity increase of $1.2 \%$ with the vertical orientation compared to the conventional distributor. Li et al. (2005) studied refrigerant flow distribution in distributors using computational fluid dynamics. In general, the authors reported that the spherical base distributor achieved the best distribution, and the orifice should be located close to the distributor base. Brix et al. (2009) studied maldistribution in an R134a mini-channel evaporator for an automotive air-conditioning system. Both inlet vapor quality and airflow non-uniformities were investigated numerically with simplified two-channel geometry. When only liquid entered into channel 2 and the remaining mixture entered channel 1 , the cooling capacity was reduced by $23 \%$. When the air velocity across channel 1 and 2 were $2.24 \mathrm{~m} \mathrm{~s}^{-1}$ and $0.96 \mathrm{~m} \mathrm{~s}^{-1}$, the cooling capacity decreased by $19 \%$.

Furthermore, different feeder tube bendings give rise to refrigerant maldistribution due to different pressure drops in the multi-channels of the evaporator. Kim et al. (2009a,b) studied both refrigerant and airflow maldistribution on a fin-and-tube five channel R410A heat pump. Two and three of the channels, respectively, were treated similarly. Essentially, there were two circuits, where one had $50 \%$ larger area than the other. It was found that the cooling capacity and COP decreased by $12 \%$ and $8 \%$ as the feeder tube diameter decreased by $25 \%$, or the inlet void fraction increased by $5.5 \%$ in one of the circuits, respectively. They also found that the cooling capacity and COP decreased by $16 \%$ and $11 \%$ when the airflow ratio between the circuits was 0.4 , keeping the total volume flow constant.

Airflow maldistribution can be compensated for to some extent with smart refrigerant circuiting. However, the refrigerant circuiting does not ensure optimized refrigerant distribution under off-design conditions. Domanski and Yashar (2007) applied a novel optimization system called ISHED (intelligent system for heat exchanger design) to optimize refrigerant circuitry in order to compensate for airflow maldistribution. They measured the air velocity profile using particle image velocimetry (PIV). When the measurements were used as an input to their simulation model, the cooling capacity increased by $4.2 \%$ using the circuitry found from ISHED, compared to an interlaced type of circuitry.

Evaporator coils are usually constructed using different types of circuiting that may interfere with refrigerant maldistribution since the channels are interconnected in the coil. The circuiting may also create maldistribution of air temperature, moisture and/or frost. In this study, we wanted to decouple each effect of maldistribution in order to perform a generic investigation of each individual maldistribution source. Each coil was simplified to two straight channels where each channel was aligned in the first row in order to have the same inlet air temperature. Furthermore, each coil was assumed to have similar flow distribution conditions. The test case was an $8.8 \mathrm{~kW}$ residential air-conditioning unit. The focus of this investigation was to study the effect of maldistri- 
bution in the evaporator. The objective was to examine the influence of the distributor, feeder tubes and the airflow on cooling capacity and COP.

This paper includes a description of the developed evaporator model in order to clarify the results presented in this paper. The model was verified by comparing to results from a commercial software program called Coil-Designer (Jiang et al., 2006). Each source of flow maldistribution was then investigated by imposing each source to the model individually. Finally, the significance of the two-phase frictional pressure drop and heat transfer correlations were investigated. Many two-phase friction and heat transfer correlations exist, and they may yield different results. We also investigated how these variables influenced the calculations of flow maldistribution. Therefore, three different twophase friction and heat transfer correlations were used in the evaporator model.

\section{Simulation model}

The main focus of the modeling was the evaporator, with which the flow maldistribution in the evaporator and its effect on system performance could be predicted. Simple quasi-static model formulations were chosen for the compressor and the expansion device. The evaporator model was a distributed mixture model and the condenser model was a moving boundary model. Both the evaporator and condenser were dynamic so that the refrigerant migration between the evaporator and the condenser could be modeled. In the present study, only steady state results are presented.

Each component model was implemented in Dymola 7.1 (2008). Dymola solvers are able to integrate largescale differential and algebraic equations (DAEs) efficiently. Dymola is based on the Modelica language and facilitates object-oriented programming, which is important for model reuse and extension. Equations can be written in a casual manner. Dymola has been well tested in the field of air-conditioning and refrigeration systems (Eborn et al., 2005; Richter, 2008). Thermophysical properties for R410A were obtained from the Refeqns package (Skovrup, 2009).

\subsection{Evaporator}

The test case evaporator was an $8.8 \mathrm{~kW}$ A-coil, i.e., two coils forming an A. Each coil had two rows of tubes and two refrigerant passes. Each refrigerant pass consisted of 18 horizontal tubes connected by U-bends. The tubes had an internal and outer diameter of 7.6 and 9.6 $\mathrm{mm}$, respectively, as well as a tube length of $444.5 \mathrm{~mm}$.
The tubes were staggered with a longitudinal and transverse tube pitch of 21.25 and $25.4 \mathrm{~mm}$. The fins were louvred and the fin pitch was $1.81 \mathrm{~mm}$. The total airside surface area was $19.2 \mathrm{~m}^{2}$.

\subsubsection{Refrigerant flow}

The focus of this study was the flow maldistribution in the evaporator. Therefore, the evaporator model had to be capable of handling the mass flow/pressure drop dependence of the refrigerant.

The simplest form of the one-dimensional two-phase flow models was chosen for this purpose, i.e. the mixture model as derived by performing a differential analysis of each phase and adding the phasic equations (Ghiaasiaan, 2008). The result is the mixture mass conservation, the mixture momentum conservation and the mixture energy conservation, given by

$$
\begin{gathered}
A \frac{\partial \bar{\rho}}{\partial t}+\frac{\partial \dot{m}}{\partial z}=0 \\
\frac{\partial \dot{m}}{\partial t}+\frac{\partial}{\partial z}\left(\frac{\dot{m}^{2}}{\rho^{\prime} A}\right)=-A \frac{\partial p}{\partial z}-F_{w} A-\bar{\rho} g A \sin \theta \\
A \frac{\partial}{\partial t}(\bar{\rho} \bar{h}-p)+\frac{\partial}{\partial z}(\dot{m} h)=P q_{w}^{\prime \prime}
\end{gathered}
$$

where it was assumed that thermodynamic equilibrium existed and that the changes in kinetic and potential energy were negligible. The mixture density, specific in situ enthalpy, specific mixed-cup enthalpy and momentum density is given by:

$$
\begin{gathered}
\bar{\rho}=\rho_{f}(1-\alpha)+\rho_{g} \alpha \\
\bar{h}=\left[\rho_{f} h_{f}(1-\alpha)+\rho_{g} h_{g} \alpha\right] / \bar{\rho} \\
h=h_{f}(1-x)+h_{g} x \\
\rho^{\prime}=\left(\frac{(1-x)^{2}}{\rho_{f}(1-\alpha)}+\frac{x^{2}}{\rho_{g} \alpha}\right)^{-1}
\end{gathered}
$$

where $\alpha$ is the void fraction and the vapor quality is defined as $x=\dot{m}_{g} / \dot{m}$.

The frictional force, $F_{w}$, the heat flux, $q_{w}^{\prime \prime}$, and the void fraction, $\alpha$, must be determined from suitable correlations. However, in this study, homogeneous flow was assumed, which means that the correlation for $\alpha$ is superfluous since $\bar{h}=h$ and $\rho^{\prime}=\bar{\rho}=\rho_{H}$. The homogeneous mixture density, $\rho_{H}$, can be shown to be equal to:

$$
\rho_{H}=\left(\frac{x}{\rho_{g}}+\frac{1-x}{\rho_{f}}\right)^{-1}
$$

Equations 1, 2 and 3 were discretized according to the Finite Volume Method (FVM). In this study, a staggered 
grid structure was adopted as described by Patankar (1980).

\subsubsection{Tube wall}

The tube wall was discretized according to the Resistance Capacitance Method (Mills, 1999). This method essentially uses the thermal resistance values to describe the heat flow across the tube element boundaries. The tube wall was assumed to have rotational symmetry. Therefore, the energy equation for each discrete cell became:

$$
M_{w} c_{p, w} \frac{d T_{w}}{d t}=\dot{Q}_{W}+\dot{Q}_{E}+\dot{Q}_{S}+\dot{Q}_{N}
$$

where $\dot{Q}_{S} / \Delta z=-P q_{w}^{\prime \prime}$ from equation 3. The entering and leaving heat flows are depicted in figure 1 .
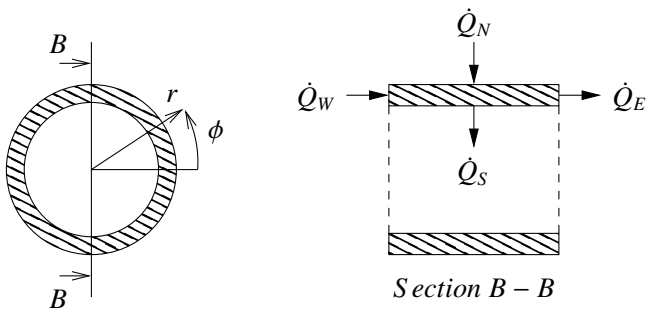

Figure 1: Heat flows to and from the tube wall

\subsubsection{Airflow}

The airflow was assumed to be incompressible and could not accumulate mass or energy. With these assumptions, the mass and energy conservation equation for each air cell became:

$$
\begin{gathered}
\dot{m}_{\mathrm{in}}-\dot{m}_{\mathrm{out}}=0 \\
\left(\dot{m} c_{p, a} T\right)_{\text {in }}-\left(\dot{m} c_{p, a} T\right)_{\text {out }}+\dot{Q}_{N}=0
\end{gathered}
$$

The effectiveness-NTU method was applied to describe the heat flow leaving the air. It describes the actual heat flow by the effectiveness, $\epsilon$, of the highest possible heat transfer, i.e.

$$
\dot{Q}_{N}=\epsilon C_{\min }\left(-\Delta T_{\max }\right)
$$

where $C_{\min }$ is the minimum capacitance flow and $\Delta T_{\max }$ is the maximum temperature difference. Appropriate effectiveness-NTU relations were applied in the twophase and superheated regions of the evaporator. Furthermore, correlations for the heat transfer coefficient and the fin efficiency must be applied.

\subsubsection{Smooth functions}

A first order continuous function was applied at the phase transitions $(0 \leq x<0.05$ and $0.95<x \leq 1)$. The function ensured a smooth transition in heat transfer correlations, frictional pressure-drop correlations and effectiveness-NTU relations. If the transitions were discontinuous, the equation solver might have been slow or even failed to converge. The first order continuous function was described in Richter (2008).

\subsubsection{Refrigerant distributor}

The feeder tubes, which were attached to the test case distributor, had an internal diameter of $3 \mathrm{~mm}$ and a length of $300 \mathrm{~mm}$. The sources of maldistribution could be either a malfunctioning distributor or different feeder tube bendings. A malfunctioning distributor could result in different phase distribution and consequently lead to different pressure drops and mass flow distributions. A different feeder tube bending could produce a different pressure drop, resulting in different mass flow distributions. In this study, we wanted to predict the mass flow distribution, which can be calculated according to the individual pressure drop in the feeder tubes and the evaporator channels. Therefore, we defined two distribution parameters: one that considered the phase distribution $F_{x}$ and another that considered the feeder tube bending $F_{\mathrm{ft}}$. Figure 2 shows a sketch of the system, which includes the symbols to be used in the following sections. Note that the zoomed-in sketch only shows one of the two coils.

The phase distribution parameter was defined by

$$
F_{x}=\frac{x_{2}}{x_{\text {in }}} \quad 0 \leq F_{x} \leq 1
$$

When $F_{x}$ was unity, the vapor quality into the feeder tubes was equal. When $F_{x}$ was zero, only liquid was fed into channel 2. Mass and energy conservation equations were applied to compute the vapor quality in channel 1. The distributor and the feeder tubes were assumed to be adiabatic.

Similarly, a feeder tube bending parameter was defined by:

$$
\begin{aligned}
& \Delta p_{\mathrm{ft}, 1}=F_{\mathrm{ft}} \Delta p_{\text {fric }, 1}+\Delta p_{\mathrm{acc}, 1} \quad 1 \leq F_{\mathrm{ft}} \leq 5.5 \\
& \Delta p_{\mathrm{ft}, 2}=\Delta p_{\text {fric }, 2}+\Delta p_{\mathrm{acc}, 2}
\end{aligned}
$$

where $F_{\mathrm{ft}}$ was multiplied to the frictional pressure drop of channel 1 only, which imposed a degree of bending (the maximum factor of 5.5 was assumed). The accelerational pressure drop is not a function of the length. Therefore, the feeder tube bending parameter can be viewed as an equivalent length multiplier. When $F_{\mathrm{ft}}$ was 


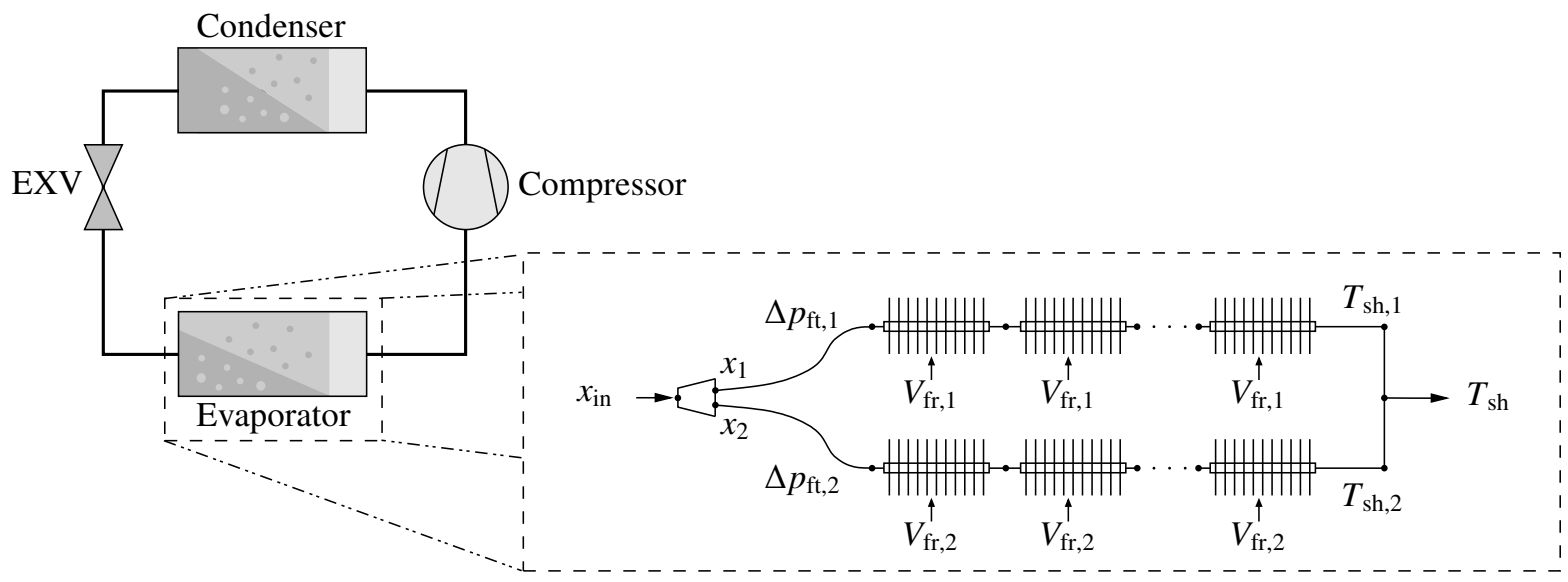

Figure 2: Sketch of the model setup

unity, the feeder tubes were straight tubes, in contrast to when $F_{\mathrm{ft}}>1$.

\subsubsection{Refrigerant manifold}

The manifold was modeled by mixing the entering streams. Mass and energy conservation equations were applied to compute the leaving mass flow and specific enthalpy. The manifold was assumed to be adiabatic with negligible pressure loss.

\subsubsection{Airflow distribution}

In order to study the airflow distribution, we have defined the airflow distribution parameter as:

$$
F_{\text {air }}=\frac{V_{\text {fr, } 2}}{V_{m}} \quad 0 \leq F_{\text {air }} \leq 1
$$

where $V_{m}$ is the mean frontal velocity across the two tubes. When $F_{\text {air }}$ was unity, the airflow was distributed equally across the two tubes. When $F_{\text {air }}$ was zero, the air flowed only across channel 1 . The mass flow rate across the evaporator was constant and the mass conservation equation was used to compute the frontal velocity of channel 1.

\subsection{Compressor}

Compressors for air-conditioning systems are rated according to EN 12900 (2005) or ANSI/AHRI Standard 540 (2004). A standard ten-coefficient polynomial can be used to calculate the mass flow rate, cooling capacity and power consumption at rated conditions (i.e., for different saturated suction and saturated discharge temperatures at fixed superheat and subcooling).

The test case compressor was assumed to be adiabatic. The model was quasi-static and employed the isentropic and volumetric efficiency to calculate the outlet thermodynamic state and volume flow rate through the compressor. The isentropic and volumetric efficiency were calculated from the rated condition of the test case compressor. These efficiencies were assumed to be independent of superheat temperature. The geometric volume flow of the compressor was $6.239 \mathrm{~m}^{3} \mathrm{~h}^{-1}$.

\subsection{Condenser}

The test case condenser had one row with four refrigerant passes. Each pass had 6 tubes that were combined into another pass that also had 6 tubes. The tube length was $2,100 \mathrm{~mm}$ with an internal and outer diameter of 7.6 and $9.6 \mathrm{~mm}$. The transverse tube pitch was $25 \mathrm{~mm}$. The fins were louvred and the fin pitch was $1.15 \mathrm{~mm}$. The total outside surface area was $52.2 \mathrm{~m}^{2}$.

The condenser was approximated as four straight channels, in which the refrigerant and air mass flow rate were distributed evenly. Maldistribution in the condenser was not addressed. Therefore, a simpler model was chosen in contrast to the distributed evaporator model, i.e. the moving boundary model. The specific model was a modified version of the model in Zhang and Zhang (2006) (which was applied to the evaporator). The moving boundary models average the vapor, two-phase and liquid regions, respectively.

The dynamics and thermal resistance of the wall were not addressed for the current model approach. However, spatial numerical integration of the two-phase heat transfer coefficient and the homogeneous void fraction were carried out. For all other heat transfer coefficients (liquid, vapor, air) as well as the fin efficiency, mean properties were used. Again, the effectiveness-NTU method was applied to calculate the heat transfer. 


\subsection{Expansion device}

The expansion device was an electrostatic expansion valve (EXV) and was modeled as an isenthalpic process. The outlet superheat of the evaporator was controlled by an integral controller (simulating the EXV) that specified the mass flow rate through the expansion valve according to a reference superheat of $5 \mathrm{~K}$.

\section{Steady state verification}

No experimental data were available that would validate the details of the two-phase flow calculations from the model. As the best possible alternative, we have verified the calculations with a commercial code (CoilDesigner, Jiang et al. (2006)). This provided us with a reasonable assessment of the reliability of the model.

The evaporator and the condenser models were verified in steady state and under uniform flow conditions with no maldistribution. The verification was carried out on a simplified tube layout corresponding to the current model geometry. Table 1 shows the correlations that were used in both Coil-Designer and the current model. Note that three different two-phase heat transfer correlations were compared for the evaporator.

Table 1: Overview of the correlations used

\begin{tabular}{ll}
\hline $\begin{array}{l}\text { Air-side } \\
\text { Heat transfer } \\
\text { Fin efficiency }\end{array}$ & $\begin{array}{l}\text { Wang et al. (1999) } \\
\text { Schmidt (1949) } \\
\text { (Schmidt approximation) }\end{array}$ \\
\hline $\begin{array}{l}\text { Single phase } \\
\text { Heat transfer } \\
\text { Friction }\end{array}$ & $\begin{array}{l}\text { Gnielinski (1976) } \\
\text { Blasius (2002) }\end{array}$ \\
\hline Two-phase (evaporator) & \\
Heat transfer & $\begin{array}{l}\text { Shah (1982) } \\
\text { Gunger and Winterton (1986) }\end{array}$ \\
Friction & $\begin{array}{l}\text { Mojtan et al. (2005b) } \\
\text { Müller-Steinhagen and Heck } \\
\text { (1986) }\end{array}$ \\
\hline Two-phase (condenser) & \\
Heat transfer & Shah (1979) \\
\hline
\end{tabular}

The steady state achieved after the start-up of the current model was used in the verification. The boundary conditions are shown in table 2. Essentially, the inlet thermodynamic states to the evaporator and condenser were needed as further input to Coil-Designer and the program computed the mass flow and capacity values to be compared. The inlet pressure and vapor quality for the evaporator were 11.18 bar $\left(11.1^{\circ} \mathrm{C}\right)$ and 0.28 , respectively. The inlet pressure and temperature to the condenser were 28.6 bar and $74.8^{\circ} \mathrm{C}$, respectively.

Table 2: Boundary conditions to the current model

\begin{tabular}{ll}
\hline Superheat & $5 \mathrm{~K}$ \\
Subcooling & $2 \mathrm{~K}$ \\
Outdoor air temperature & $35^{\circ} \mathrm{C}$ \\
Outdoor frontal air velocity & $0.68 \mathrm{~m} \mathrm{~s}^{-1}$ \\
Indoor air temperature & $26.7^{\circ} \mathrm{C}$ \\
Indoor frontal air velocity & $1.16 \mathrm{~m} \mathrm{~s}^{-1}$ \\
Number of cells (evaporator) & 30 \\
\hline
\end{tabular}

Table 3 shows the comparison of the computed mass flow rate and capacity for both the evaporator and the condenser.

Table 3: Comparison of mass flow rate and capacity, $(\mathrm{CM}=$ current model, $C D=$ Coil-Designer)

\begin{tabular}{lccc}
\hline & & $\begin{array}{c}\text { Capacity } \\
{[\mathrm{kW}]}\end{array}$ & $\begin{array}{c}\text { Mass flow } \\
{\left[\mathrm{kg} \mathrm{s}^{-1}\right]}\end{array}$ \\
\hline Evaporator & & & \\
Shah (1982) & CM & 10297 & 0.0668 \\
& CD & 11116 & 0.0726 \\
& Error & $7.4 \%$ & $8.0 \%$ \\
\hline Gunger and Winterton & CM & 10704 & 0.0693 \\
(1986) & CD & 11492 & 0.075 \\
& Error & $6.9 \%$ & $7.6 \%$ \\
\hline Wojtan et al. (2005b) & CM & 10544 & 0.0682 \\
& CD & 10703 & 0.0699 \\
& Error & $1.5 \%$ & $2.4 \%$ \\
\hline Condenser & & & \\
Shah (1979) & CM & 12859 & 0.0668 \\
& CD & 12372 & 0.0645 \\
& Error & $3.9 \%$ & $3.6 \%$ \\
\hline
\end{tabular}

The first two comparisons of the evaporator showed larger differences than the third comparison. This difference was mainly due to the smooth functions that were applied at the two-phase to vapor phase transition as described in section 2.1.4. The result was a smaller heat transfer in the current model, since the two-phase heat transfer coefficient and the heat exchanger effectiveness decreased faster towards the vapor region values. This change is depicted in figure 3 in terms of temperature profiles throughout the evaporator from the first comparison. The air temperature difference of the current model decreased before the point of full evaporation and before the refrigerant temperature started to rise.

The third comparison of the evaporator involved a newer correlation for the two-phase heat transfer coeffi- 


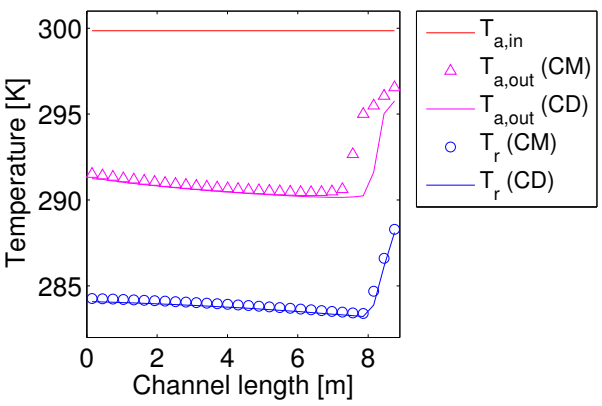

Figure 3: Comparison of the temperature profiles of the evaporator using Shah (1982) correlation (CM=current model, $\mathrm{CD}=$ Coil-Designer)

cient that already predicted a decrease in the heat transfer coefficient in the two-phase region (i.e., onset of dryout). This new correlation resulted in a better comparison, since the smoothing process of the current model had less impact.

Note that the total cooling capacity of the evaporator was higher than the rated $8.8 \mathrm{~kW}$. This high value was due to the simplified tube layout in which each channel was aligned in the first row. The channels meet a higher inlet air temperature than they would have if they were aligned in the second row.

The current condenser model averaged the two-phase and single-phase regions. However, the mass flow rate and the capacity were in good agreement. Figure 4 shows the temperature profile comparison with CoilDesigner. Note that the refrigerant temperature of the current model is drawn linearly throughout the vapor, two-phase and liquid regions. The outlet air temperature also has a mean in each region.

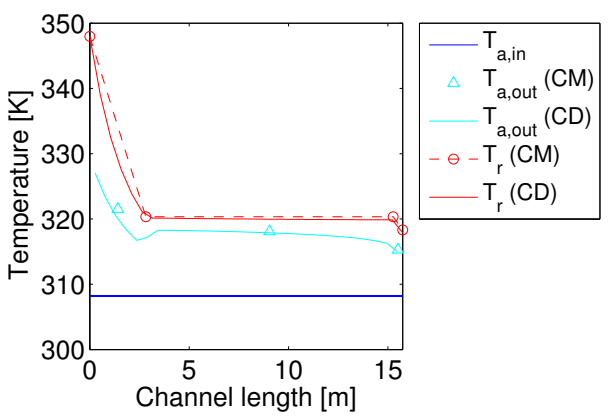

Figure 4: Comparison of the temperature profiles of the condenser ( $\mathrm{CM}=$ current model, $\mathrm{CD}=$ Coil-Designer $)$

The temperature profile comparison was in good agreement and we concluded that both the evaporator and condenser models were verified in steady state with Coil-Designer, which already has been validated exper- imentally. Therefore, the models were suitable for further analysis of maldistribution.

\section{Results}

The results of the simulations of maldistribution are presented in this section. The simulation continues from the verified steady state in section 3 with similar conditions from table 2 and parameters from section 2. Each maldistribution source was imposed to the model individually by varying the phase distribution parameter, $F_{x}$, the feeder tube bending parameter, $F_{\mathrm{ft}}$, and the airflow distribution parameter, $F_{\text {air }}$.

The correlations from table 1 were used and the correlation of Shah (1982) was chosen to model two-phase heat transfer in the evaporator. Some of the results are shown for three different two-phase frictional correlations in order to study their effect on maldistribution, which is discussed in section 4.4. Otherwise, the correlation of Müller-Steinhagen and Heck (1986) was used.

\subsection{Maldistribution from the distributor}

The distribution of refrigerant mass flow as a function of the phase distribution parameter, $F_{x}$, is shown in figure 5a.

This figure shows that the mass flow distribution was dependent on $F_{x}$, so more mass came through the channel with lower inlet vapor quality (channel 2) and less mass came through the channel with higher inlet vapor quality (channel 1). This is determined by the pressure drop across the channels that must be equal. Indeed, more mass travels through a channel with lower vapor quality since the pressure drop of the liquid phase is lower than the pressure drop of the vapor phase.

The consequence of refrigerant maldistribution can be seen in figure $5 \mathrm{~b}$, which shows individual superheat values. At $F_{x}=0.8$, liquid was flowing out of channel 2. These points are important because the two-phase area of the evaporator decreases when full evaporation is not reached. A larger superheated area in channel 1 will be required in order to evaporate this surplus liquid. Therefore, the overall UA-value decreased.

Since the UA-value decreased, the cooling capacity, COP and evaporation temperature decreased as shown in figures $5 \mathrm{c}$ and $6 \mathrm{a}$. The capacity of the channel that received more mass flow increased, but the capacity of the channel that received less mass flow decreased even more and the total cooling capacity of the coil decreased.

Figure $6 \mathrm{~b}$ also shows a zoomed-in $\log (p) h$ diagram of the thermodynamic states in the distributor, feeder 
(a)

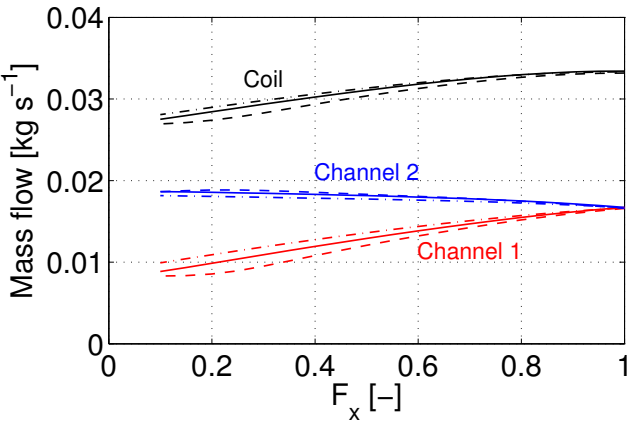

(b)

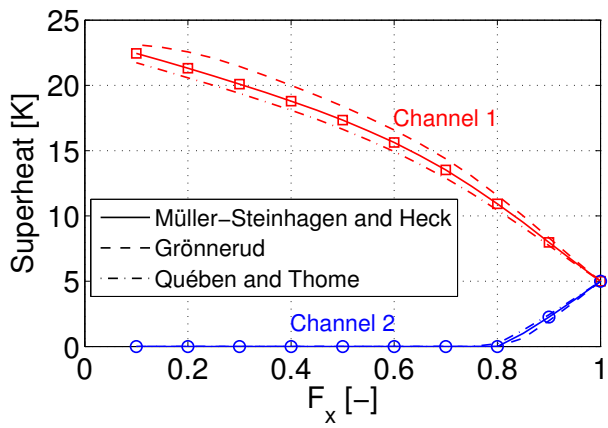

(c)

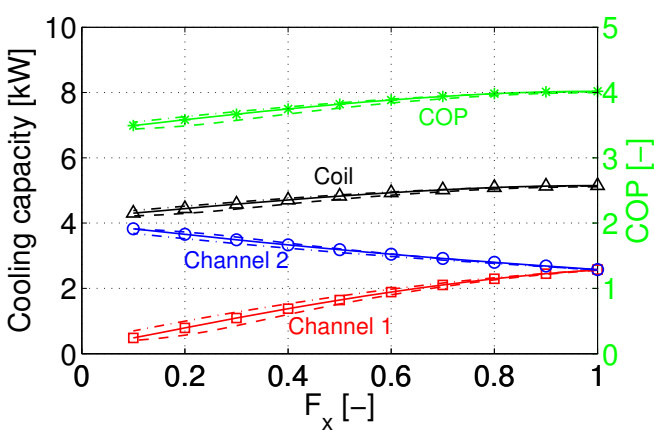

Figure 5: Selected parameters vs. the phase distribution parameter

tubes, evaporator channels and the manifold. The figure also shows that the pressure drop ratios between the feeder tubes and evaporator channels were altered as the phase distribution parameter decreased. For channel 1, the pressure drop through the feeder tube increased. For channel 2, the pressure drop through the feeder tube decreased.

The total cooling capacity and COP decreased by $16.4 \%$ and $13 \%$, respectively, as $F_{x}$ changed from 1 to 0.1 .

\subsection{Maldistribution from the feeder tubes}

The distribution of refrigerant mass flow, superheat, cooling capacity and COP are shown in figure 7 as functions of the feeder tube bending parameter. (a)

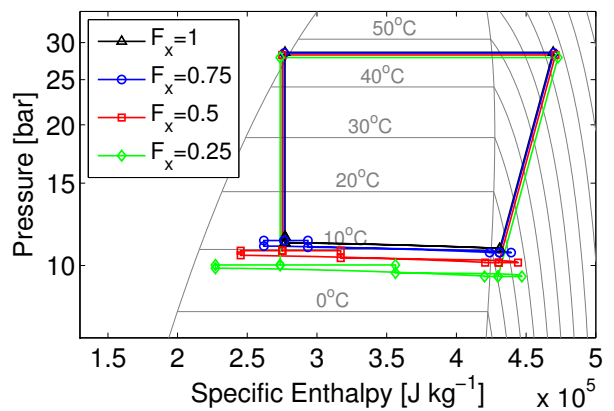

(b)

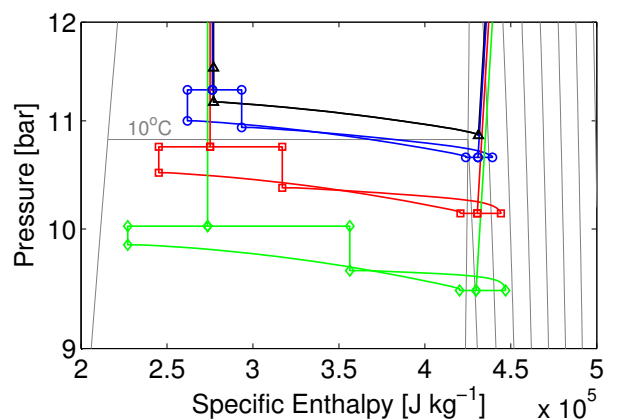

Figure 6: $\log (p) h$ cycles at different phase distribution parameters

A similar mass flow distribution trend was seen for different feeder tube bendings as $F_{\mathrm{ft}}$ increased towards 5.5. The pressure drop through feeder tube 1 became higher than that for feeder tube 2 . Therefore, more refrigerant traveled through channel 2 in order to ensure an equal pressure drop through the channels. The fact that more mass traveled through channel 2 also resulted in a higher pressure drop in channel 2, and thus had some compensating effect. The trend of the superheat curves might indicate this effect. Liquid started to flow out of channel 2 at $F_{\mathrm{ft}}=2.75$.

The total mass flow in each coil did not decrease to the same degree as when we considered the inlet liquid/vapor maldistribution. This also resulted in a smaller reduction in cooling capacity and COP. It showed that maldistribution from different feeder tube bendings was insignificant compared to inlet liquid/vapor maldistribution. The two are not considered to interact significantly, i.e. the distribution of liquid and vapor phase is a separation phenomenon in the distributor, and thus not affected by the pressure drop through the feeder tubes.

Note that a compact fin-and-tube heat-exchanger consists of a number of tubes connected by U-bends. The presence of $U$-bends reduces the influence of the feeder tube pressure drop on the total pressure drop, and hence its effect on maldistribution. 
(a)

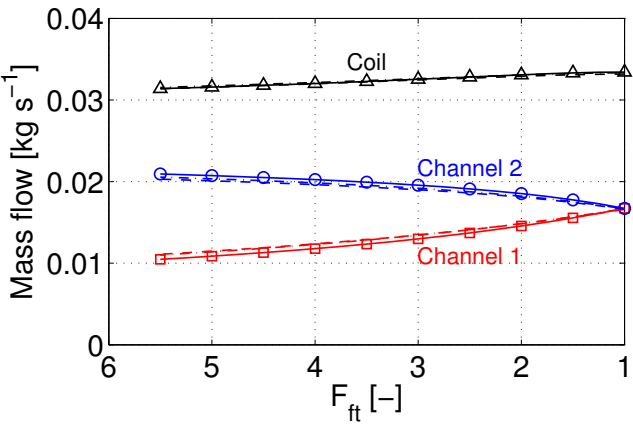

(b)

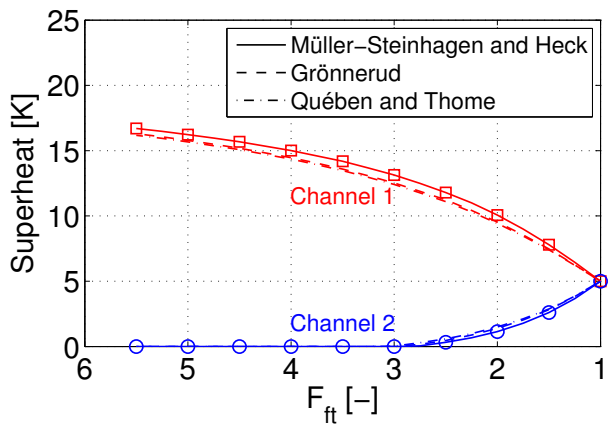

(c)

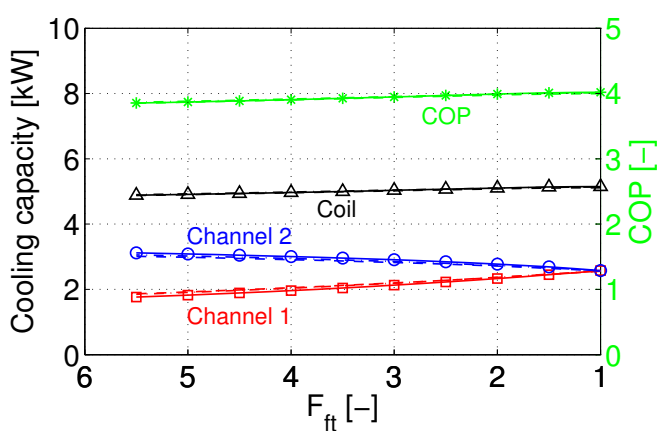

Figure 7: Selected parameters vs. the feeder tube bending parameter

Figure 8a shows the corresponding $\log (p) h$ diagram. It shows that the evaporation temperature decreased, but that the decrease was not significant. Figure $8 \mathrm{~b}$ indicates that the small decrease in the evaporation temperature was caused by the increased pressure drop through the feeder tubes, which was higher for feeder tube 1.

The cooling capacity and COP decreased by $5.2 \%$ and $4.1 \%$, as $F_{\mathrm{ft}}$ went from 1 to 5.5 .

\subsection{Maldistribution from the airflow}

The distribution of refrigerant mass flow, superheat, cooling capacity and COP are shown in figure 9 as functions of the airflow distribution parameter.

Interestingly, the mass flow distribution was almost equal in each channel as $F_{\text {air }}$ decreased. However, both (a)

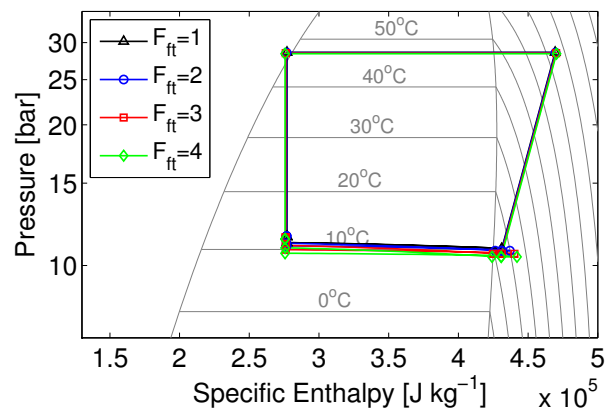

(b)

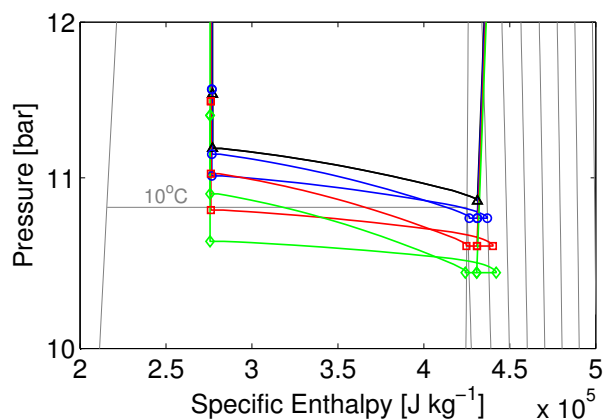

Figure 8: $\log (p) h$ cycles at different feeder tube bending parameter

mass flows were reduced significantly in order to ensure the overall superheat temperature of $5 \mathrm{~K}$. The simultaneous reduction of the mass flows with different superheated areas had a significant degrading effect on cooling capacity and COP.

As $F_{\text {air }}$ approached 0.1 , there was nearly an air blockage of channel 2. Of course, this occurrence was impractical, but the model indicated that a channel that receives almost no airflow (which could also be a recirculation zone in the coil) would have liquid refrigerant flowing through it that must be evaporated. Unfortunately, the refrigerant will be evaporated by the increased superheat of the other channels. This is also indicated in figure $9 \mathrm{~b}$, where the superheat of channel 1 increased quite drastically. The result was a decrease in overall UA-value, cooling capacity and COP.

The evaporating temperature also decreased quite drastically as seen in figure 10a. Figure 10b shows that the feeder tube pressure drop was almost identical for each channel. Furthermore, the ratio of the feeder tube pressure drop to the evaporator channel pressure drop did not change as the airflow distribution parameter decreased.

The cooling capacity and the COP decreased by $49.9 \%$ and $43.2 \%$ as $F_{\text {air }}$ went to 0.1 .

Other types of evaporators were studied in Kim et al. $(2009 b, a)$ and Brix et al. $(2009,2010)$. Yet, the results 
(a)

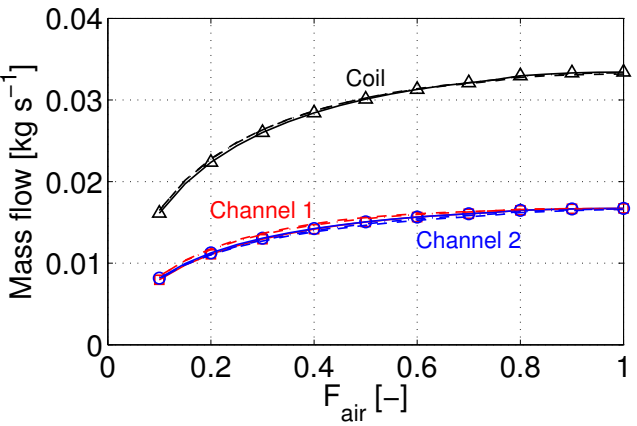

(b)

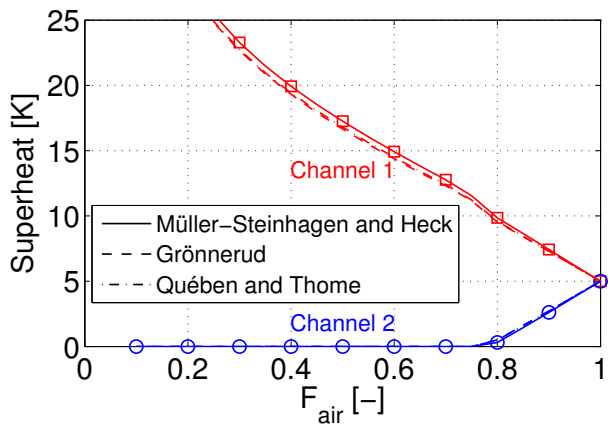

(c)

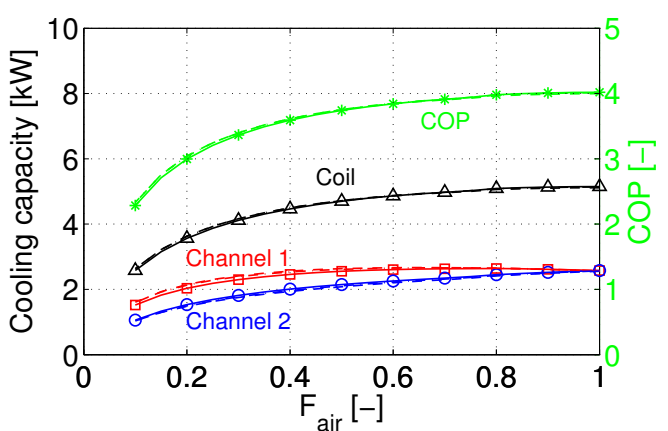

Figure 9: Selected parameters vs. the airflow distribution parameter

from sections 4.1, 4.2 and 4.3 yielded similar results and trends concerning the maldistribution of flow.

\subsection{Significance of the choice of correlations}

Figures $5 a-5 c, 7 a-7 c$ and $9 a-9 c$ show the results of three different two-phase frictional pressure drop correlations from the literature.

1. Müller-Steinhagen and Heck (1986)

2. Grönnerud (1979)

3. Quibén and Thome (2007)

We have chosen to use two of the most well known traditional correlations (1-2) along with a more sophisticated, newer correlation (3). The traditional correlations were somewhat simple compared to the latter, which is (a)

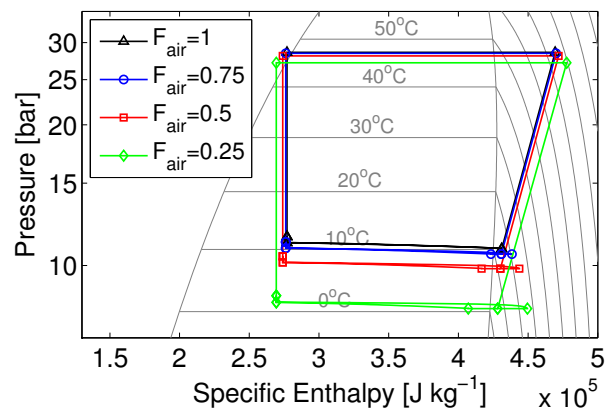

(b)

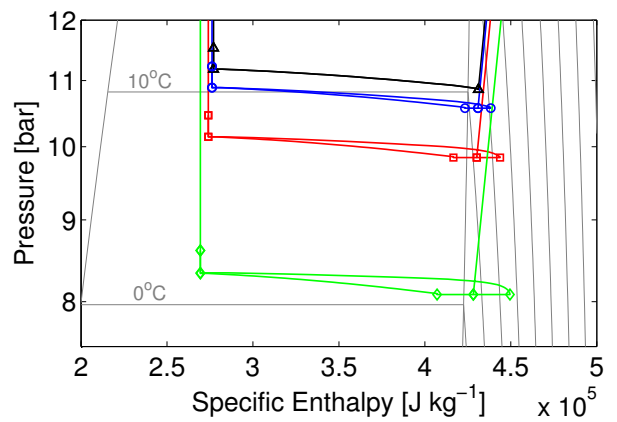

Figure 10: $\log (p) h$ cycles at different airflow distribution parameter

a phenomenological correlation that involves the prediction of flow regimes during evaporation. However, when correlation 3 was applied, the first correlation was used to model the frictional pressure drop of the feeder tubes, since correlation 3 showed unreasonable frictional pressure gradients at high mass fluxes in the feeder tubes.

The total pressure drop across the channels was different for all the correlations. Yet, the difference in terms of cooling capacity and COP were insignificant as depicted in figure $5 \mathrm{c}, 7 \mathrm{c}$ and $9 \mathrm{c}$. The distribution of mass flow and cooling capacity for each channel might indicate small differences, but the total difference was quite similar. As such, the choice of the twophase frictional pressure drop correlation was insignificant when studying maldistribution effects from the distributor, feeder tubes and airflow, for the RAC unit that was being studied.

Figure 11 shows the results of the cooling capacity and COP for three different two-phase heat transfer correlations from the literature at different $F_{x}, F_{\mathrm{ft}}$ and $F_{\text {air }}$. The curves coincided for all three. The correlations were as follows:

1. Shah (1982)

2. Gunger and Winterton (1987)

3. Wojtan et al. (2005b) 
(a)

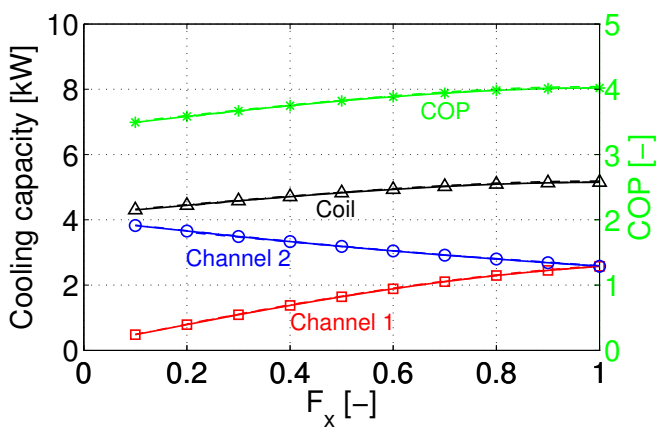

(b)

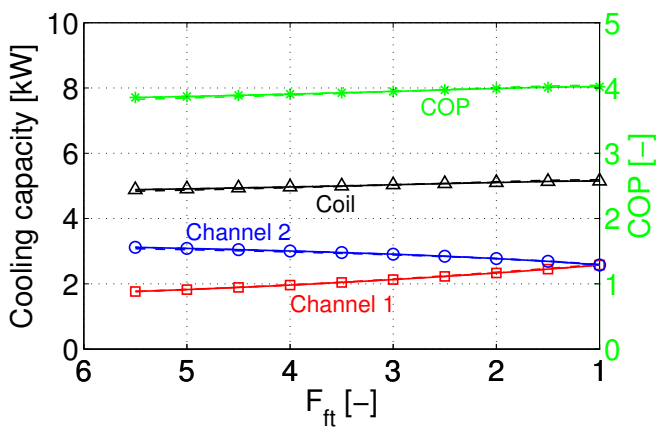

(c)

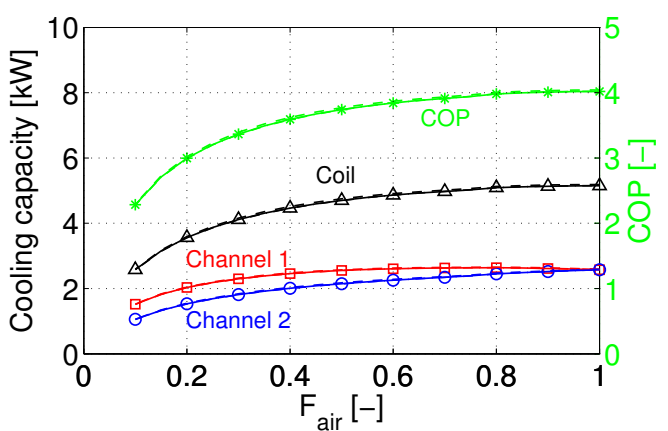

Figure 11: Individual channel and coil cooling capacity and COP vs. the different distribution parameters. The results are given for different heat transfer correlations

Again, two well known traditional two-phase heat transfer correlations (1-2) were chosen together with a more sophisticated and newer correlation (3). Correlation 3 used the same flow map (Wojtan et al., 2005a) for flow regime prediction as for the frictional pressure drop correlation that Quibén and Thome (2007) used previously.

The cooling capacities and COP values were not affected much by the choice of correlation. Thus, the changes were insignificant when the maldistribution effects were studied. The verification shown in table 3 suggests that the cooling capacity should be different by up to $7 \%$ when applying different two-phase heat transfer correlations. However, the inlet thermodynamic state and superheat were fixed in that comparison. In the present simulation, the inlet thermodynamic state was not fixed and the evaporating temperature varied between the simulations. The cooling capacity was compensated for by a lower evaporation temperature in the system. Yet, the change in evaporation temperature was small and did not have a significant impact on system performance in terms of COP as indicated in figure 11.

Note that the correlation from Gunger and Winterton (1987) was not available in Coil-Designer. Thus, the earlier correlation from Gunger and Winterton (1986) was used for the comparison in section 3 . The newer correlation was recommended in a study by Thome (1996). Therefore, the newer correlation was used here.

A similar study of the significance of different two-phase flow correlations was carried out on minichannels by Brix et al. (2010). They also found that the choice of different two-phase flow correlations did not significantly affect the predicted maldistribution in terms of the degradation in cooling capacity.

\section{Conclusion}

A system model of an R410A residential airconditioning system was developed and verified against the program Coil-Designer. The model was capable of simulating flow maldistribution in the evaporator as well as the effect of flow maldistribution on system performance.

We concluded that maldistribution in fin-and-tube evaporators reduced the cooling capacity and COP of the system whenever the source was a malfunctioning distributor, different feeder tube bendings or a nonuniform airflow. With the current definitions of the distribution parameters in this study, we showed that nonuniform airflow significantly reduced the cooling capacity and COP. The different liquid/vapor distribution in the distributor had a smaller impact. Different feeder tube bendings had a minor effect on the degradation of the cooling capacity and COP. The results showed a decrease in COP as much as $13 \%, 4.1 \%$ and $43.2 \%$ for different liquid/vapor distribution in the distributor, different feeder tube bendings and non-uniform airflow, respectively.

In this study, the individual effects of maldistribution were considered. However, in practice, we may have combined maldistribution. The individual sources may act together to reduce the cooling capacity even fur- 
ther or these sources may actually compensate for each other.

For a given system, it is difficult to determine the airflow distribution parameter or liquid/vapor distribution parameter, which can be different for different types of evaporators and operating conditions. Therefore, the results of this paper should be used as a guideline for pursuing a detailed understanding of the individual sources and effects of maldistribution in evaporators.

The results and trends are similar when different twophase frictional and heat transfer correlations were used. Therefore, the significance of the choice of two-phase flow correlation was minor in predicting flow maldistribution.

AbdelAziz, O., Singh, V., Aute, V., Radermacher, R., 2008. A-type heat exchanger simulation using 2-d cfd for airside heat transfer and pressure drop. In: 12th International Refrigeration and Air Conditioning Conference at Purdue. No. 2200. West Lafayette, IN, USA.

ANSI/AHRI Standard 540, 2004. Standard For Performance Rating Of Positive Displacement Refrigerant Compressors And Compressor Units. Air-Conditioning, Heating, and Refrigeration Institute, Arlington, VA 22201, USA.

Blasius, P. R. H., 2002. VDI Wärmeatlas, 9th Edition. SpringerVerlag, Ch. Lab.

Brix, W., Kærn, M. R., Elmegaard, B., 2009. Modelling refrigerant distribution in microchannel evaporators. International Journal of Refrigeration 32 (7), 1736 - 1743.

Brix, W., Kærn, M. R., Elmegaard, B., 2010. Modelling distribution of evaporating $\mathrm{co} 2$ in parallel minichannels. International Journal of Refrigeration 33 (6), 1086 - 1094.

Domanski, P. A., Yashar, D., 2007. Application of an evolution program for refrigerant circuitry optimization. In: ACRECONF "Challenges To Sustainability". New Delhi, India.

Dymola 7.1, 2008. Dynamic Modeling Laboratory, Dymola User's Manual, version 7.1. Dynasim AB, Research Park Ideon SE-223 70, Lund, Sweden.

Eborn, J., Tummescheit, H., Prö1ß, K., 2005. Airconditioning - a modelica library for dynamic simulation of ac systems. In: 4th International Modelica Conference. Hamburg, Germany, pp. 185-192.

EN 12900, 2005. Refrigerant compressors - Rating conditions, tolerances and presentation of manufacturer's performance data. European Committee for Standardization, Brussels.

Ghiaasiaan, S. M., 2008. Two-phase flow: Boiling and Condensation in Conventional and Miniature Systems, 1st Edition. Cambridge University Press.

Gnielinski, V., 1976. New equation for heat and mass transfer in turbulent pipe and channel flow. International Chemical Engineering 16, 359-368.

Grönnerud, R., 1979. Investigation of liquid hold-up, flow-resistance and heat transfer in circulation type of evaporators, part iv: Twophase flow resistance in boiling refrigerants. In: Annexe 1972-1, Bull. de l'Inst. du Froid.

Gunger, K., Winterton, R., 1986. A general correlation for flow boiling in tubes and annuli. International Journal of Heat and Mass Transfer 29, 351-358.

Gunger, K., Winterton, R., 1987. Simplified general correlation for saturated flow boiling and comparison of correlations with data Chem. Eng. Res. Des. 65, 148-156.

Jiang, H., Aute, V., Radermacher, R., 2006. Coildesigner: A general- purpose simulation and design tool for air to refrigerant heat exchangers. International Journal of Refrigeration 29, 601-610.

Kim, J.-H., Braun, J., Groll, E., 2009a. Evaluation of a hybrid method for refrigerant flow balancing in multi-circuit evaporators. International Journal of Refrigeration 32, 1283-1292.

Kim, J.-H., Braun, J., Groll, E., 2009b. A hybrid method for refrigerant flow balancing in multi-circuit evaporators: Upstream versus downstream flow control. International Journal of Refrigeration 32, 1271-1282.

Lee, J., Kwon, Y.-C., Kim, M. H., 2003. An improved method for analyzing a fin and tube evaporator containing a zeotropic mixture refrigerant with air maldistribution. International Journal of Refrigeration 26, 707-720.

Li, G., Frankel, S., Braun, J. E., Groll, E. A., 2005. Application of cfd models to two-phase flow in refrigeration distributors. HVAC\&R Research 11 (1), 45-62.

Mills, A. F., 1999. Heat Transfer, 2nd Edition. Prentice Hall.

Müller-Steinhagen, H., Heck, K., 1986. A simple friction pressure drop correlation for two-phase flow in pipes. Chemical engineering and processing 20, 297-308.

Nakayama, M., Sumida, Y., Hirakuni, S., Mochizuki, A., 2000. Development of a refrigerant two-phase flow distributor for a room air conditioner. In: 8th International Refrigeration Conference at Purdue. West Lafayette, IN, USA, pp. 313-319.

Patankar, S., 1980. Numerical heat transfer and fluid flow. Taylor \& Francis.

Payne, W. V., Domanski, P. A., 2003. Potential benefits of smart refrigerant distributors. Final report No. ARTI-21CR/610-20050-01, Air-Conditioning and Refrigeration Technology Institute, Arlington, VA, USA.

Quibén, J., Thome, J., 2007. Flow pattern based two-phase frictional pressure drop model for horizontal tubes, part ii: New phenomenological model. International Journal of Heat and Fluid Flow 28, 1060-1072.

Richter, C. C., 2008. Proposal of new object-oriented equation-based model libraries for thermodynamic systems. Ph.D. thesis, Technische Universität Carolo-Wilhelmina zu Braunschweig, Fakultät für Maschinenbau.

Schmidt, T. E., 1949. Heat transfer calculations for extended surfaces. Refrigerating Engineering, 351-357.

Shah, M. M., 1979. A general correlation for heat transfer during film condensation inside pipes. International Journal of Heat and Mass Transfer 22, 547-556.

Shah, M. M., 1982. Chart correlation for saturated boiling heat transfer: Equations and further study. ASHRAE Transactions 88, 185196.

Skovrup, M. J., 2009. Thermodynamic and thermophysical properties of refrigerants. Department of Energy Engineering, Technical University of Denmark, Nils Koppels Allé, Building 402, DK-2800 Lyngby, Denmark.

Thome, J., 1996. Boiling of new refrigerants a state-of-the-art review. International Journal of Refrigeration 19, 435-457.

Wang, C.-C., Lee, C.-J., Chang, C.-T., Lin, S.-P., 1999. Heat transfer and friction correlation for compact louvered fin-and-tube heat exchangers. International Journal of Heat and Mass Transfer 42, 1945-1956.

Wojtan, L., Ursenbacher, T., Thome, J., 2005a. Investigation of flow boiling in horizontal tubes: Part $\mathrm{i}$ - a new diabatic two-phase flow pattern map. International Journal of Heat and Mass Transfer 48, 2955-2969.

Wojtan, L., Ursenbacher, T., Thome, J., 2005b. Investigation of flow boiling in horizontal tubes: Part ii - development of a new heat transfer model for stratified-wavy, dryout and mist flow regimes. International Journal of Heat and Mass Transfer 48, 2970-2985.

Zhang, W.-J., Zhang, C.-L., 2006. A generalized moving-boundary 
model for transient simulation of dry-expansion evaporators under larger disturbances. International Journal of Refrigeration 29, 1119-1127. 